\title{
A Mössbauer Study of the Low Spin-High Spin Transition of an Oxygen Adduct Formed in Solid $\beta$-Fe(II)Phthalocyanine
}

\author{
Houping Yin $^{\mathrm{a}}$, Shiro Kubuki ${ }^{\mathrm{b}}$, Zoltán Homonnay ${ }^{\mathrm{c}}$, Ernő Kuzmann*,d, Attila Vértes ${ }^{\mathrm{d}}$, Yen Wei ${ }^{\mathrm{a}}$ and \\ Amar Nath \\ ${ }^{a}$ Department of Chemistry, Drexel University, Philadelphia, PA 19104, USA \\ ${ }^{b}$ Department of Chemical and Biological Engineering, Ube National College of Technology, Yamaguchi 755-8555, \\ Japan \\ ${ }^{c}$ Institute of Chemistry, Eötvös University, P.O.Box 32, 1512 Budapest, Hungary \\ ${ }^{d}$ Laboratory of Nuclear Chemistry, Chemical Research Center, HAS, P.O.Box 32, 1512 Budapest, Hungary \\ ${ }^{e}$ Department of Chemistry, University of North Carolina, Asheville, NC 28804, USA
}

\begin{abstract}
Several oxygen adducts are formed when oxygen is diffused into the interplanar spacings of solid $\beta-\mathrm{Fe}^{\mathrm{II}} \mathrm{Pc}$ suspended in water. The constraints imposed by the solid matrix induce formation of interesting oxygen adducts which cannot be synthesized by regular solution chemistry. One of the oxygen adducts exhibits low-spin to high-spin transition with considerable thermal hysteresis.
\end{abstract}

Keywords: Fe-phthalocyanine, oxygenation, Mössbauer spectroscopy, temperature dependence, oxygen adducts, spin crossover.

\section{INTRODUCTION}

Phthalocyanines have been widely used as electrochemical catalysts, photosensitizers of $\mathrm{TiO}_{2}$ electrodes, gas sensors and as regular heterogeneous catalysts [1-6]. Exposure to oxygen, iodine, and bromine increases their conductivity by several orders of magnitude due to p-type doping. Similarly, lithium doping induces n-type conductivity. The two well characterized polymorphic forms of phthalocyanines are $\alpha$ and $\beta$-. The main difference in the two forms is the orientation of the flat molecules with respect to the crystallographic axis, where the perpendicular distance between the stacks of molecules remains approximately the same, namely 0.338 $\mathrm{nm}$. The inclination of the molecular stacks in the $\beta$ polymorph is much larger than that in the $\alpha$-form. Consequently, the distance between the central metal atoms in the adjoining stacks is about $0.48 \mathrm{~nm}$ in the $\beta$-form versus 0.38 $\mathrm{nm}$ in the $\alpha$-form. In the $\beta$-form, the nitrogen atoms in the neighboring molecules are present axially above and below the central metal atom at a distance of about $0.338 \mathrm{~nm}$. The Mössbauer isomer shifts and quadrupole splittings for the $\beta$ polymorphs of $\mathrm{Co}^{\mathrm{II}} \mathrm{Pc}$ and $\mathrm{Fe}^{\mathrm{II}} \mathrm{Pc}$ are larger in magnitude than the ones observed for the $\alpha$-form because of the interaction of the $\pi$-electrons of the aromatic rings of the neighboring molecules, through the nitrogens with the $3 \mathrm{~d}_{\mathrm{xy}}, 3 \mathrm{~d}_{\mathrm{yz}}$ orbitals of the central $\mathrm{Fe}(\mathrm{Co})$ atom [7].

There is considerable interest in the interaction of oxygen with phthalocyanines [4-6] partly, because of the use of oxygen adducts for the formation of $\mathrm{Co}$ and $\mathrm{Fe}$ nanoparticles

*Address correspondence to this author at the Laboratory of Nuclear Chemistry, Chemical Research Center, HAS, P.O.Box 32, 1512 Budapest, Hungary; E-mail: kuzmann@ludens.elte.hu coated with carbon [8-10]. Recently, we reported formation of a variety of oxygen adducts with $\mathrm{Fe}^{\mathrm{II}} \mathrm{Pc}$ which are stabilized in the solid matrix and do not exist in solution [11].

\section{EXPERIMENTAL}

Needle shaped crystals of pure $\beta-\mathrm{Fe}^{\mathrm{II}} \mathrm{Pc}$ were obtained by sublimation of the commercial material. After grinding, the powder was suspended in water maintained at $50^{\circ} \mathrm{C}$. Oxygen was bubbled through the suspension for more than 6 weeks. Part of the material was taken out and dried in vacuum. With the other, argon is bubbled for a few weeks while maintaining the suspension at $50^{\circ} \mathrm{C}$, to check the stability of oxygen adducts and also to remove freely floating diatomic oxygen, if any is present. Both materials showed similar behavior, therefore, the presence of freely floating oxygen was not confirmed, and the stability of the oxygen adduct was affirmed.

${ }^{57} \mathrm{Fe}$ Mössbauer spectra of the samples were recorded with a conventional Mössbauer spectrometer (WISSEL) in transmission geometry between $78 \mathrm{~K}$ and $300 \mathrm{~K}$, in a temperature-controlled cryostat (Leybold, Germany). Isomer shifts are relatively given to $\alpha$-iron. A ${ }^{57} \mathrm{Co} / \mathrm{Rh} \gamma$-radiation source $3.6 * 10^{9} \mathrm{~Bq}$ activity was used. The Mössbauer spectra were analyzed by the least-squares, fitting of Lorentzian lines using the MOSSWINN code [12].

\section{RESULTS AND DISCUSSION}

The Mössbauer spectra showed very interesting changes with temperature. We attributed the spectral changes at low temperature to coordinate with a freely floating $\mathrm{O}_{2}$ molecule in the sixth axial position of a five-coordinate $\mu$-oxo bridged or $\mu$-peroxo bridged $\mathrm{Fe}^{\mathrm{III}} \mathrm{Pc}$. Such free $\mathrm{O}_{2}$ molecules have 


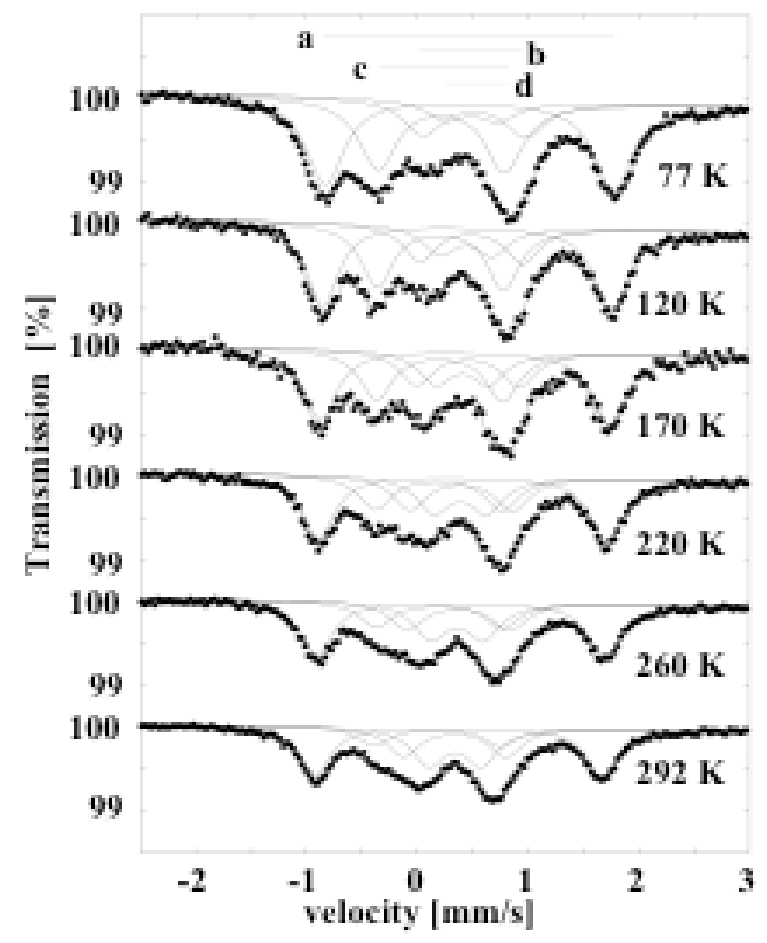

Fig. (1). Temperature dependence of the Mössbauer spectra of $\beta$ Fe-Phthalocyanine $\left(\mathrm{Fe}^{\mathrm{II}} \mathrm{Pc}\right)$, treated with bubbling oxygen in aqueous suspension at $50^{\circ} \mathrm{C}$ for more then 6 weeks. The interconversion of the LS species (c) to HS species (d) with increasing temperature is observed.

been reported for $\mathrm{Pb}^{\mathrm{II}} \mathrm{Pc}$ and $\mathrm{Zn}{ }^{\mathrm{II}} \mathrm{Pc}[4,5,13]$. We assumed that the bonding with $\mathrm{O}_{2}$, was weak due to constraints im- posed in the solid matrix and that the bond ruptured at higher temperatures. Here we report that it is not necessary to assume free $\mathrm{O}_{2}$ molecules in the channels between the stacks of $\mathrm{Fe}^{\mathrm{II}} \mathrm{Pc}$ and the spectral changes can be interpreted as highspin to low-spin transition in an unusual adduct of $\mathrm{Fe}^{\mathrm{Il}} \mathrm{Pc}$ formed with the help of constraints imposed by the solid matrix.

The Mössbauer spectra obtained at different temperatures are shown in Fig. (1). One can see clearly a dramatic change in the spectral envelope. The spectra were computer analyzed and fit with four species, the original pristine $\mathrm{Fe}^{\mathrm{II}} \mathrm{Pc}$ with large quadrupole splitting (a) and three oxygen adducts (b, c, and d) formed with $\mathrm{Fe}^{\mathrm{II}} \mathrm{Pc}$. The data obtained from the computer fit are shown in Table 1. One can see that the isomer shifts for each species, show a slight decrease in temperature as expected (see also in Fig. 2). The quadrupole splittings was constrained to be the same at all temperatures in a simultaneous fitting of the six spectra.

The abundances (normalized areas) of the different species are plotted as a function of temperature as shown in Fig. (3). The non-oxygenated pristine $\mathrm{Fe}^{\mathrm{II}} \mathrm{Pc}$ is designated as (a) and one of the oxygen adducts (b) exhibit minor changes in the abundance with temperature. The minor variations for (a) and (b) probably arise from the differences in the DebyeWaller factors at different iron sites in the lattice. It is obvious from the plots that species (c) which is abundant at low temperatures is converted into species (d) as the temperature increases. The sum of their abundances is approximately the same, namely $42 \%$ units. The isomer shift of the high spin oxygen adduct (d) is significantly larger than that of the low spin (c). On the other hand, the quadrupole splitting changes the reverse order as expected for $\mathrm{Fe}^{\mathrm{III}}$ compounds [14]. There

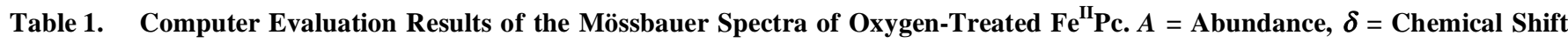
and $\Delta=$ Quadrupole Splitting

\begin{tabular}{|c|c|c|c|c|c|c|}
\hline$T[\mathbf{K}]$ & \multicolumn{3}{|c|}{ species (a) } & \multicolumn{3}{|c|}{ species (b) } \\
\hline 77 & $41.3(4)$ & $0.473(2)$ & $2.605(4)$ & $17(4)$ & $0.520(8)$ & $0.93(7)$ \\
\hline 120 & $39.8(4)$ & $0.451(2)$ & $2.605(4)$ & $17(4)$ & $0.492(9)$ & $0.93(6)$ \\
\hline 170 & $38(1)$ & $0.432(4)$ & $2.605(9)$ & $19(4)$ & $0.46(1)$ & $0.93(4)$ \\
\hline 260 & $37.5(5)$ & $0.396(2)$ & $2.605(5)$ & $20(2)$ & $0.376(7)$ & $0.93(4)$ \\
\hline 292 & $36.9(4)$ & $0.377(2)$ & $2.605(4)$ & $22(1)$ & $0.34(6)$ & $0.93(3$ \\
\hline \multirow{2}{*}{$T[\mathbf{K}]$} & \multicolumn{3}{|c|}{ species (c) } & \multicolumn{3}{|c|}{ species $(d)$} \\
\hline & $A[\%]$ & $\delta[\mathrm{mm} / \mathrm{s}]$ & $\Delta[\mathrm{mm} / \mathrm{s}]$ & $A[\%]$ & $\delta[\mathrm{mm} / \mathrm{s}]$ & $\Delta[\mathrm{mm} / \mathrm{s}]$ \\
\hline 220 & $20(1)$ & $0.197(8)$ & $1.14(2)$ & $21(2)$ & $0.391(6)$ & $0.474(2)$ \\
\hline 260 & $18(1)$ & $0.203(5)$ & $1.14(1)$ & $25(2)$ & $0.363(4)$ & $0.474(2)$ \\
\hline 292 & $13(1)$ & $0.185(7)$ & $1.14(1)$ & $27(2)$ & $0.343(3)$ & $0.474(2)$ \\
\hline
\end{tabular}


is considerable thermal hysteresis, and therefore (d) and (c) coexist as has been reported earlier for some HS-LS transitions in $\mathrm{Fe}^{\mathrm{III}}$ complexes [14]. The abundance of (c) and (d) also depends on the rate of cooling.

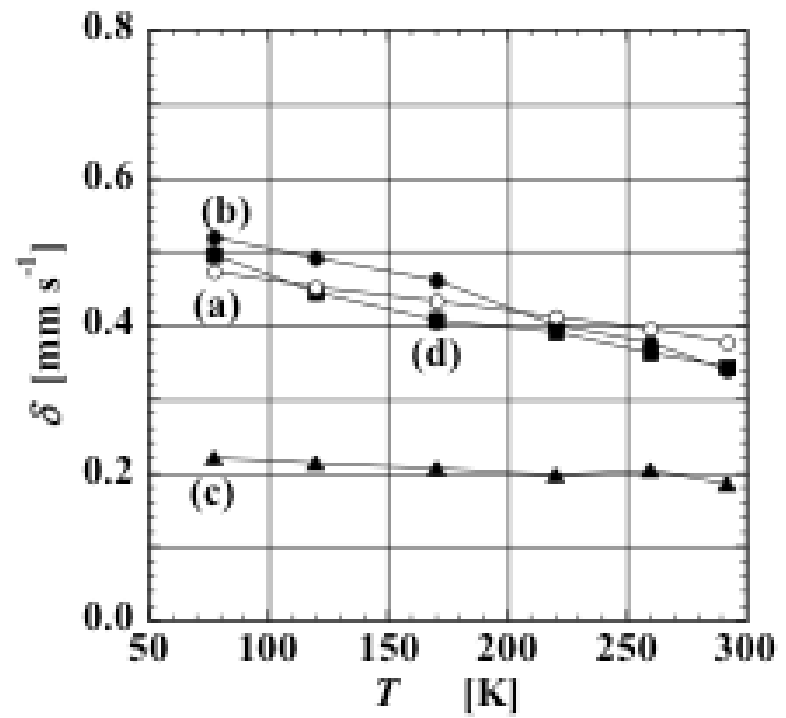

Fig. (2). Temperature dependence of the isomer shifts of doublets (a), (b), (c), and (d) obtained from the Mössbauer spectra of oxygen treated $\mathrm{Fe}^{\mathrm{II}} \mathrm{Pc}$.

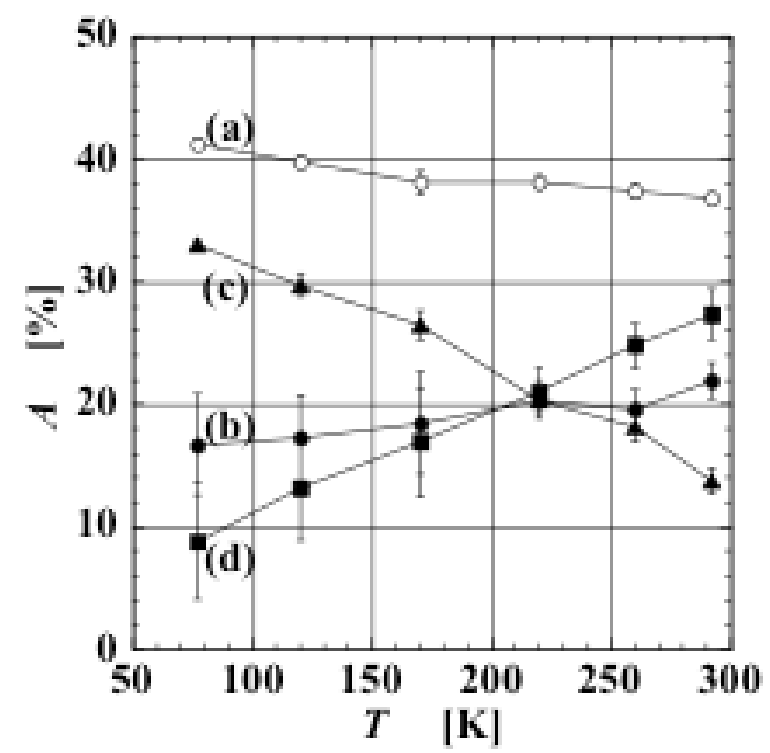

Fig. (3). Temperature dependence of the absorption area of doublets (a), (b), (c), and (d) obtained from the Mössbauer spectra of oxygen treated $\mathrm{Fe}^{\mathrm{II}} \mathrm{Pc}$.

After reviewing the Mössbauer parameters of several $\mu$ oxo bridged dimers of $\mathrm{Fe}^{\mathrm{III}}$ and $\mathrm{Fe}^{\mathrm{II}}$ phthalocyanines [15-17] and taking into account the distance between iron atoms in adjoining stacks, we propose formation of $\mu$-peroxo bridge on one of the axial positions of $\mathrm{Fe}^{\mathrm{III}} \mathrm{Pc}$ and a bond with $\mathrm{O}_{2}$ (sideways or end-on) on the other axial position as shown in Fig. (4). Such bonding has been proposed earlier between iron atoms for a model compound of an enzyme [18] and also for an iron-copper complex [19]. It is likely that the iron atom in the high spin (d) is situated slightly out-of-plane towards the peroxo bridge due to tension in the bridge. At lower temperatures, the channels between the stacks presumably shrink a little and the $\mathrm{Fe}^{\mathrm{III}}$ atom flips in the Pc plane.

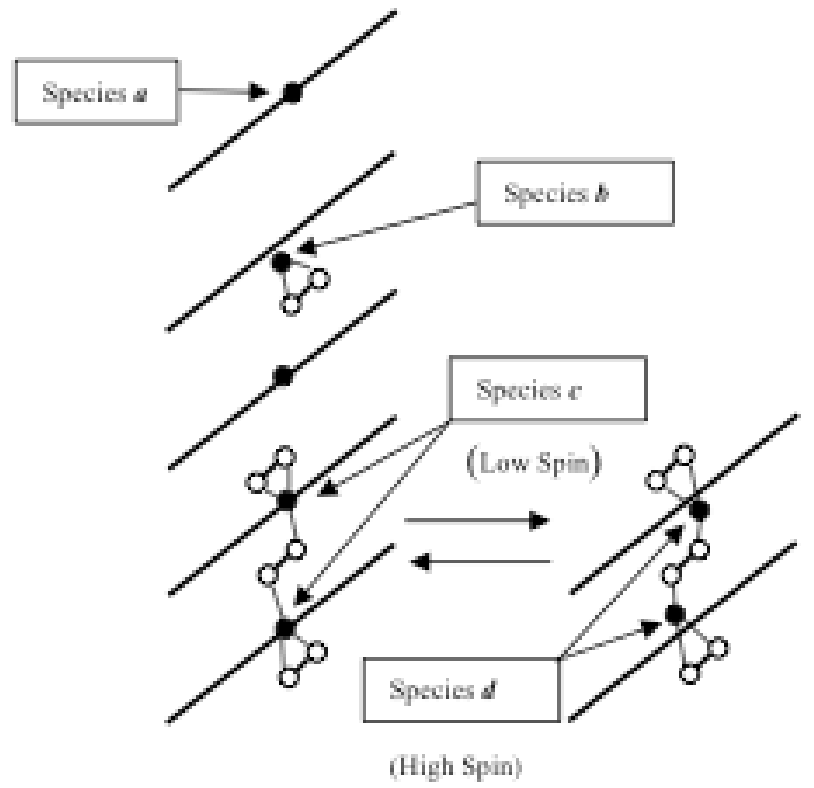

Fig. (4). Schematic presentation of the four species observed in oxygenated solid $\mathrm{Fe}^{\mathrm{II}} \mathrm{Pc}$. The tilted bars show the plane of the $\mathrm{Pc}$ rings stacked in the lattice; black and white circles represent iron and oxygen atoms, respectively.

Oxygen is bonded pretty strongly as no differences were observed in the spectra of the material which was subjected to thermal treatment in an inert ambient. One can speculate that in the oxygen adduct (b), $\mathrm{Fe}^{\mathrm{III}}$ is attached to $\mathrm{O}_{2}$ on one of the axial positions, forming a high spin five-coordinate compound with $\mathrm{Fe}$ atom slightly out of the plane.

\section{CONCLUSION}

Based on the temperature dependent changes, observed in the Mösssbauer parameters of subspectra belonging to oxygen adducts in oxygenated $\beta$-phthalocyanine a low spinhigh spin crossover of one of the oxygen adducts has been shown.

\section{ACKNOWLEDGMENT}

This work was supported by OTKA grants No. T043687, K068135, K067835 and T062691. The authors thank Mr Attila Horváth for his technical help. AN was supported by PRF(ACS).

\section{REFERENCES}

[1] Zagel, J. H. Coord. Chem. Rev., 1998, 119, 89-136.

[2] Meunier, B.; Sorokin, A. Acc. Chem. Res., 1991, 30, 470-476.

[3] Chen, M. J.; Rathke, J. W. Trends Inorg. Chem., 1998, 5, 29-41.

[4] McKeon, N.B. "Phthalocyanine Materials", Cambridge Univ. Press 1998

[5] Guillaud, G.; Simon, J.; Germain, J. P. Coord. Chem. Rev., 1998 178-80, 1443-1484.

[6] Thomas, A. L. "Phthalocyanine:Research and Applications", CRC Press, Boca Raton, Florida (1990)

[7] Srivastava,T.S.; Przbylinski, J. L.; Nath, A. Inorg. Chem., 1974, 13 , 1562-1564. 
[8] Nath, A.; Kopelev, N.; Tyagi, S. D.; Chechersky, V.; Wei, Y. Mater. Lett., 1993, 16, 39-44.

[9] Kopelev, N. S.; Chechersky, V.; Nath, A.; Wang, Z. L.; Kuzmann,E.; Zhang,B.; Via, G.H. Chem. Mater., 1995, 7, 1419-1421.

[10] Kuzmann,E.; Nath, A.; Chechersky, V., Li, S.; Wei, Y.; Chen, X.; Li, J.; Homonnay, Z.; Gál, M.; Garg, V. K.; Klencsár, Z.; Vértes, A. Hyperfine Inter., 2002, 139/140, 631.

[11] Kuzmann, E.; Homonnay, Z.; Vertes, A.; Li, S.; Yin,H.; Wei,Y.; Nath, A.; Chen, X.; Li, J. J. Solid State Chem., 2003, 170, 118-123.

[12] Klencsár, Z; Kuzmann, E.; Vértes, A., J. Radioanal. Nucl. Chem., 1996, 210, 105-112.

[13] Kerp, H. R.; Westerduin, K. T.; van Veen, A. T.; van Faasen, E. E., J. Mater. Res., 2001, 16, 503-511.

[14] Van Koningsbruggen, P. J.; Maeda, Y.; Oshio, H., Top. Curr. Chem., 2004, 233, 259-324.
[15] Ercolani, C.; Floris, B. in "Phthalocyanines: Properties and Applications, Leznoff, C. C.; Lever, A.B.P. Eds.VCH, New York, 1993 Vol. 2, pp. 5-41.

[16] Hanack, M.; Keppeler, U.; Lange, A.; Hirsch, A.; Dieing, R. in "Phthalocyanines: Properties and Applications, Leznoff, C. C.; Lever, A. B. P. Eds. VCH, New York, 1993, Vol 2. pp. 47-96.

[17] Ercolani, C.; Floris, B.in "Phthalocyanine:Properties and Applications, Vol.4. Leznoff, C. C.; Lever, A.B.P. Eds. VCH, New York, 1996, pp. 409-425.

[18] Kim, K.; Lippard, S. J. J. Am. Chem. Soc., 1996, 118, 4914-4915.

[19] Chishiro, T.; Shimazaki, Y.; Tani, F.; Tachi, Y.; Naruta, Y.; Karasawa, S.; Hayami, S.; Maeda, Y. Angew. Chem. Int. Ed., 2003, 42, 2788-2791.

Received: March 31, 2008

Revised: April 23, 2008

Accepted: May 02, 2008

(C) Yin et al.; Licensee Bentham Open.

This is an open access article distributed under the terms of the Creative Commons Attribution License (http://creativecommons.org/licenses/by/2.5/), which permits unrestrictive use, distribution, and reproduction in any medium, provided the original work is properly cited. 